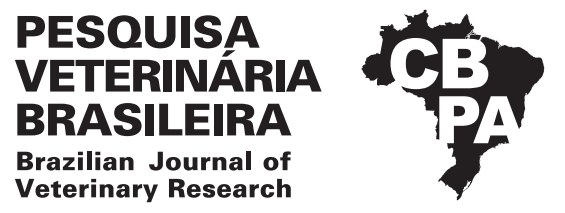

Pesq. Vet. Bras. 38(9):1787-1792, setembro 2018 DOI: 10.1590/1678-5150-PVB-5028

Artigo Original

Pequenos Animais/Small Animals Diseases

ISSN 0100-736X (Print)

ISSN 1678-5150 (Online)

\title{
Efeitos do banho prévio, da tricotomia e da antissepsia na redução da contaminação do sítio cirúrgico em cadelas submetidas à $\mathrm{OSH}_{\text {eletiva }}{ }^{1}$
}

\author{
Lylian K.G. Medeiros ${ }^{2 *}$, Renato O. Rego ${ }^{2}$, Meire Maria da Silva ${ }^{2}$, \\ Fernanda V. Henrique ${ }^{2}$, Kalyne D.S. Oliveira ${ }^{3}$, Felício G. Júnior ${ }^{2}$, Almir P. Sousa ${ }^{2}$ \\ e Pedro I. Nóbrega Neto ${ }^{2}$
}

\begin{abstract}
Medeiros L.K.G., Rego R.O., Silva M.M., Henrique F.V., Oliveira K.D.S., Garino Júnior F., Sousa A.P. \& Nóbrega Neto P.I. 2018. [Effects of the previous bath, trichotomy and antisepsis in reducing contamination of the surgical site in bitches undergoing elective OSH.] Efeitos do banho prévio, da tricotomia e da antissepsia na redução da contaminação do sítio cirúrgico em cadelas submetidas à OSH eletiva. Pesquisa Veterinária Brasileira 38(9):1787-1792. Centro de Saúde e Tecnologia Rural, Universidade Federal de Campina Grande, Av. Universitária s/n, Bairro Santa Cecília, Patos, PB 58708-110, Brazil. E-mail: lyliankarlla@hotmail.com

The objective of this study was to analyze the influence of bath 24 hours before surgery and preoperative shaving in reducing microbial count of the operating field skin and antiseptic efficiency of $0.5 \%$ chlorhexidine gluconate and $10 \%$ iodine polyvinylpyrrolidone for antisepsis of the surgical site, by checking its action 4 minutes and 2 hours after application. We used 20 healthy bitches, randomly allocated into 2 groups of 10 animals: Group I underwent bath 24 hours before surgery, whereas Group II did not undergo this procedure. Many bacterial genera have been isolated before and after use of antiseptics. Statistical significance was observed between the groups regarding the effect of bath prior to surgery, just two hours after application of chlorhexidine. Shaving reduced $26.48 \%$ of the microbial load in Group I and increased the microbial load in $41.19 \%$ in Group II, showing statistical difference. After the use of antiseptics, there was no statistical difference between the groups at any time. Similarly, comparison of the efficiency of the bath with or without antiseptic showed no statistical significance. The iodine polyvinylpyrrolidone caused allergic reaction in $15 \%$ of animals and was not observed skin irritation caused by chlorhexidine. We conclude that the prior bath is effective in reducing bacterial load just after 2 hours of antisepsis with chlorhexidine; shaving is more effective in reducing microbial when the animal is subjected to the bath and the two antiseptic agents are equally effective in surgical antisepsis or for up to 2 hours the animal did not take a bath or prior to surgery.
\end{abstract}

INDEX TERMS: Previous bath, trichotomy, antisepsis, contamination of the surgical site, ovariosalpingohisterectomy, elective OSH, antiseptic, operative field, chlorhexidine, PVP-I, bitches, surgery.

\footnotetext{
${ }^{1}$ Recebido em 24 de março de 2017.

Aceito para publicação em 8 de novembro de 2017.

${ }^{2}$ Programa de Pós-Graduação em Medicina Veterinária, Centro de Saúde e Tecnologia Rural (CSTR), Universidade Federal de Campina Grande (UFCG), Av. Universitária s/n, Bairro Santa Cecília, Patos, PB 58708-110, Brasil. E-mails: renato_otaviano@yahoo.com.br, meiremacedo@yahoo.com.br, nandinhavh@gmail.com, garinofjr@hotmail.com, almir@cstr.ufcg.edu.br, pedroisidro@ymail.com; *Autor para correspondência: lyliankarlla@hotmail.com

${ }^{3}$ Programa de Pós-Graduação em Ciência Animal, Universidade Federal Rural do Semi-Árido (UFERSA), Av. Francisco Mota 572, Bairro Costa e Silva, Mossoró, RN 59625-900, Brasil.E-mail: kalyne_danielly@hotmail.com
}

RESUMO.- 0 objetivo deste estudo foi analisar a influencia do banho 24 horas antes do procedimento cirúrgico e da tricotomia pré-operatória na redução da contagem microbiana da pele do campo operatório, bem como a eficiência antisséptica do gluconato de clorexidina $0,5 \%$ e da polivinilpirrolidona iodada $10 \%$ para antissepsia do sítio cirúrgico, verificando sua ação 4 minutos e 2 horas após aplicação. Utilizaram-se 20 cadelas hígidas, alocadas ao acaso em 2 grupos de 10 animais: os 
animais do Grupo I foram submetidos ao banho 24 horas antes do procedimento cirúrgico, enquanto os do Grupo II não passaram por este procedimento. Foram isolados diversos gêneros bacterianos antes e após o uso dos antissépticos. Significância estatística foi verificada entre os grupos quanto ao efeito do banho prévio à cirurgia, apenas 2 horas após a aplicação de clorexidina. A tricotomia reduziu 26,48\% da carga microbiana nos animais do Grupo I e elevou a carga microbiana em 41,19\% nos animais do Grupo II, revelando diferença estatística. Após o uso dos antissépticos, não foi observada diferença estatística entre os grupos em nenhum momento. Do mesmo modo, a comparação da eficiência dos antissépticos com ou sem banho, não revelou significância estatística. A polivinilpirrolidona iodada causou reação alérgica em 15\% dos animais e não foi observada irritação cutânea causada pela clorexidina. Conclui-se que o banho prévio tem efeito na redução da carga bacteriana apenas após 2 horas de antissepsia com clorexidina; a tricotomia é mais eficaz na redução microbiana quando o animal é submetido ao banho e os dois antissépticos são igualmente eficazes na antissepsia cirúrgica por até 2 horas quer o animal tome banho ou não previamente à cirurgia.

TERMOS DE INDEXAÇÃO: Banho prévio, tricotomia, antissepsia, contaminação do sítio cirúrgico, ovariosalpingo-histerectomia, OSH eletiva, antisséptico, campo operatório, clorexidina, PVP-I, cadelas, cirurgia.

\section{INTRODUÇÃO}

A infecção do sítio cirúrgico constitui um aspecto preocupante devido à sua alta taxa de morbidade e mortalidade (Oliveira et al. 2002). É determinada por diversos fatores, entre eles, quantidade e tipo de contaminação, técnica cirúrgica e anestésica empregada e resistência do individuo (Rocha 2008). Na medicina veterinária, estudos observaram índices de infecção do sítio cirúrgico de 5,9 a 9,5\% (Bernis Filho et al. 1998, Nicholson et al. 2002, Braga 2008, Arias et al. 2013).

A prevenção da infecção representa aspecto determinante para evitar as complicações pós-cirúrgicas (Reis 2014). A administração profilática de antimicrobianos é muito utilizada no controle de infecções cirúrgicas (Braga et al. 2012), contudo, o emprego errôneo desses fármacos favoreceu o aparecimento de microrganismos resistentes, diminuindo a eficiência desta prática (Oliveira et al. 2011). Assim sendo, a forma mais eficaz de prevenção da infecção cirúrgica é através do uso de uma técnica asséptica rigorosa, que envolve a preparação do paciente, da equipe cirúrgica, esterilização dos equipamentos, preparação das instalações cirúrgicas, emprego de uma técnica operatória adequada e cuidados pós-operatórios (Cockshutt 2007).

Quanto à preparação do paciente, preconiza-se a realização do banho 24 horas antes da cirurgia, a remoção dos pelos imediatamente antes do procedimento e antissepsia do local cirúrgico (Silva et al. 2009). A antissepsia consiste em um processo que inibe ou extermina os microrganismos de um determinado ambiente, através do uso de antissépticos (Moriya \& Módena 2008) e representa papel essencial no procedimento cirúrgico, devendo agir sobre os microrganismos presentes na pele (Monteiro et al. 2001, Magalini et al. 2013). A microbiota da pele é classificada como residente e transitória, sendo a residente composta pelas bactérias que habitam normalmente a pele, e a transitória pelas adquiridas pelo contato direto com o ambiente. Os microrganismos residentes na pele canina são Staphylococcus epidermitis, Corynebacterium spp. Micrococcus spp. e Pityrosporum spp. Os transitórios são Staphylococcus aureus, Streptococcus spp., Staphylococcus intermedius e Escherichia coli (Silva et al. 2009).

Segundo Garcia (2010) embora a utilização de antissépticos seja muito difundida, ainda não se sabe de fato qual o que possui maior eficácia. Dentre os antissépticos utilizados, destacam-se a clorexidina, um antisséptico pertencente ao grupo das biguanidas que possui amplo espectro de ação, tem mínima absorção sistêmica e efeito rápido e duradouro (Ibáñez \& Casamada 2005) e a polivinilpirrolidona iodada (PVP-I) um composto hidrossolúvel de polivinilpirrolidona e iodo, efetivo contra bactérias, vírus e fungos (Delucia 2007).

Desta forma, os objetivos deste estudo foram analisar a influência do banho realizado 24 horas antes do procedimento cirúrgico e da tricotomia imediatamente antes do procedimento na redução da contagem microbiana da pele do campo operatório, bem como a eficiência antisséptica do gluconato de clorexidina 0,5\% e da PVP-I 10\% para antissepsia do sítio cirúrgico, verificando sua ação 4 minutos e 2 horas após aplicação.

\section{MATERIAL E MÉTODOS}

Este estudo foi realizado no Centro Cirúrgico e no Laboratório de Microbiologia do Hospital Veterinário da UFCG, em Patos/PB. Foram utilizdas 20 cadelas hígidas, sem alterações cutâneas, de raças, pesos e idades variadas, provenientes da rotina clínico-cirúrgica do referido Hospital, as quais foram submetidas ao procedimento de ovariohisterectomia eletiva. Após autorização por escrito dos proprietários e parecer favorável do Comitê de Ética em Pesquisa da UFCG (protocolo 216/2014), os animais foram alocados, ao acaso, em dois grupos de igual quantidade: os animais do Grupo I foram submetidos ao banho 24 horas antes do procedimento cirúrgico, enquanto que os animais do Grupo II não foram submetidos ao banho. 0 banho nos animais do Grupo I foi realizado por veterinários no Hospital Veterinário com xampu comercial neutro para cães, onde o mesmo era aplicado nos pelos previamente molhados por todo o corpo do animal e em seguida removido com água limpa, sendo mantidos internados até a realização do procedimento.

As amostras de pele foram coletadas na região abdominal retroumbilical, no sentido craniocaudal e lateral, com auxílio de swabs estéreis embebidos em água peptonada $0,1 \%$ estéril, contida em tubo de ensaio, retornando ao mesmo tubo imediatamente após a coleta. A área de coleta da amostra foi delimitada com o auxílio de moldes de papel estéril, com uma janela medindo $4 \times 4$ centímetros. Em cada animal a antissepsia foi realizada com os dois antissépticos, sendo um lado do abdome com PVP-I 10\% (com 1\% de iodo ativo) e o outro com clorexidina $0,5 \%$. 0 lado a ser tratado com clorexidina foi escolhido através de sorteio no primeiro animal e a partir do segundo animal inverteu-se continuamente os lados tratados com cada antisséptico, de modo que ambos os produtos fossem utilizados equitativamente em ambos os quadrantes (direito e esquerdo) do abdome.

As amostras foram identificadas segundo o local de onde foram coletadas e o momento da coleta: na linha média, antes da tricotomia (M1), na linha média, imediatamente após a tricotomia (M2), na área preparada com clorexidina, quatro minutos após sua aplicação (M3c), na área preparada com PVP-I, quatro minutos após sua aplicação (M3p), na área preparada com clorexidina, duas 
horas após sua aplicação (M4c), e na área preparada com PVP-I, duas horas após sua aplicação (M4p). A tricotomia foi realizada no pré-operatório, 15 minutos antes da antissepsia, com tricótomo de navalha convencional, empregando apenas água limpa.

As amostras obtidas foram agitadas por 1 minuto e em seguida diluídas em até $10^{-4}$. De cada diluição, foram retiradas alíquotas de $1 \mathrm{ml}$ e plaqueadas em duplicata pelo método de "Pour Plate" em meio Plate Count Agar (PCA), previamente fundido e resfriado a $45^{\circ} \mathrm{C}$. As placas foram incubadas a $37^{\circ} \mathrm{C}$ por 48 horas para contagem das Unidades Formadoras de Colônia (UFC) $/ \mathrm{cm}^{2}$. As amostras foram também semeadas em meio de cultura Ágar sangue ovino 5\% para avaliação dos aspectos morfológicos das colônias e morfotintoriais à técnica de Gram. Foi inoculado $0,1 \mathrm{ml}$ de cada diluição em placa previamente preparada, com auxílio de uma alça de Drigalski, espalhando-se o inóculo por toda a superfície, sendo incubadas a $37^{\circ} \mathrm{C}$ e para realização da leitura após 48 horas. Para identificação de bactérias gram-positivas foram realizadas as provas da catalase, oxidase e coagulase, além da produção de urease, reação de VogesProskauer (VP), redução de nitrato, hidrólise de esculina e fermentação dos açúcares: D-Manitol, D-Manose, trealose, xilose, maltose, lactose, arabinose, rafinose e sacarose. Para a identificação de bactérias gramnegativas foram realizadas as provas bioquímicas de TSI, motilidade, SIM, malonato, produção de indol, produção de urease, produção de gelatinase, produção de fenilalanina desaminase, utilização de citrato, reação de vermelho de metila (VM) e Voges-Proskauer (VP), fermentação da lactose, hidrólise de esculina e redução de nitrato. Os microrganismos isolados foram identificados com base em Murray (1999).

0 percentual de redução bacteriana após a tricotomia (M2), 4 minutos após a antissepsia com clorexidina (M3c) e PVP-I (M3p) e duas horas após a antissepsia com clorexidina (M4c) e PVP-I (M4p), em cada grupo, foi calculado com um modelo matemático adaptado de Osuna et al. (1990), apresentado a seguir:

Redução de bactérias $(\%)$ após a tricotomia $=\frac{\text { UFC no M1 }- \text { UFC no M2 x } 100}{\text { UFC no M1 }}$

Redução de bactérias (\%) 4 minutos após antissepsia com clorexidina (M3c) e PVP-I (M3p) e duas horas após a antissepsia com Clorexidina (M4c) e PVP-I (M4p):

Redução de bactérias (\%) após antissepsia $=\frac{\text { UFC no M2 }- \text { UFC no M3c, M3p, M4c ou M4p x } 100}{\text { UFC no M2 }}$

Para comparar a eficácia média dos antissépticos, mensurou-se o percentual médio de redução bacteriana, utilizando as mesmas fórmulas citadas acima empregando os 20 animais do experimento, sem distinção entre grupos.

Os dados obtidos foram analisados com o programa Bioestat 5.3, ao nível de significância de $5 \%(\mathrm{p}<0,05)$. A quantidade de colônias de bactérias obtidas em cada tratamento foi analisada empregando o teste $t$ de Student para os dados que apresentavam distribuição normal, e o teste $U$ de Mann-Whitney para os de distribuição não normal. A comparação dos dois antissépticos foi realizada sem distinção de grupos através do teste $U$ de Mann-Whitney. Os dados de distribuição normal são apresentados como média \pm desvio padrão e os de distribuição não normal como mediana desvio interquartílico.

\section{RESULTADOS}

Todas as amostras coletadas antes do uso de antissépticos (M1 e M2) apresentaram crescimento bacteriano. Os gêneros isolados estão disponíveis no Quadro 1.
Os dados referentes ao crescimento de UFC por cm nos Grupos I e II estão disponíveis na Fig.1. Não foi observada significância estatística ao comparar os momentos M1, M2, M3c, M3p e M4p do Grupo I com o Grupo II. Porém, ao comparar o M4c dos dois grupos foi constatada diferença estatística $(p<0,05)$, indicando que após 2 horas de antissepsia com clorexidina os animais que foram submetidos ao banho prévio apresentaram menor número de UFC por $\mathrm{cm}^{2}$.

Quadro 1. Bactérias isoladas e respectiva frequência absoluta, em cadelas submetidas à ovariohisterectomia

\begin{tabular}{|c|c|c|}
\hline Momentos & Grupo I & Grupo II \\
\hline M1 & $\begin{array}{l}\text { Klebsiella pneumoniae }(3 / 10) \\
\text { Acinetobacter } \text { sp. }(2 / 10) \\
\text { Bacillus sp. }(2 / 10) \\
\text { Micrococcus sp. }(2 / 10) \\
\text { Staphylococcus aureus }(2 / 10) \\
\text { S. xylosus }(2 / 10) \\
\text { Corynebacterium sp. }(1 / 10) \\
\text { Escherichia coli }(1 / 10) \\
\text { S. chromogenes }(1 / 10) \\
\text { S. epidermidis }(1 / 10) \\
\text { S. intermedius }(1 / 10) \\
\text { S. lugdunensis }(1 / 10) \\
\text { S. saprophyticus }(1 / 10)\end{array}$ & $\begin{array}{l}\text { Bacillus sp. }(4 / 10) \\
\text { S. aureus }(4 / 10) \\
\text { Acinetobacter } \text { sp. }(2 / 10) \\
\text { Micrococcus sp. }(2 / 10) \\
\text { S. chromogenes }(2 / 10) \\
\text { S. saprophyticus }(2 / 10) \\
\text { Streptococcus sp. }(2 / 10) \\
\text { Corynebacterium sp. }(1 / 10) \\
\text { E. coli }(1 / 10) \\
\text { Pseudomonas sp. }(1 / 10) \\
\text { S. intermedius }(1 / 10) \\
\text { S. xylosus }(1 / 10)\end{array}$ \\
\hline M2 & $\begin{array}{l}\text { S. aureus }(4 / 10) \\
\text { S. saprophyticus }(3 / 10) \\
\text { Corynebacterium sp. }(2 / 10) \\
\text { S. chromogenes }(2 / 10) \\
\text { Bacillus sp. }(1 / 10) \\
\text { Klebsiella pneumoniae }(1 / 10) \\
\text { Micococcus sp. }(1 / 10) \\
\text { Pseudomonas sp. }(1 / 10) \\
\text { S. intermedius }(1 / 10) \\
\text { S. lugdunensis }(1 / 10) \\
\text { S. xylosus }(1 / 10)\end{array}$ & $\begin{array}{l}\text { S. aureus }(4 / 10) \\
\text { Micrococcus sp. }(3 / 10) \\
\text { Corynebacterium sp. }(2 / 10) \\
\text { S. chromogenes }(2 / 10) \\
\text { S. intermedius }(2 / 10) \\
\text { S. saprophyticus }(2 / 10) \\
\text { Bacillus } \text { sp. }(1 / 10) \\
\text { E. coli }(1 / 10) \\
\text { S. epidermidis }(1 / 10) \\
\text { S. lugdunensis }(1 / 10)\end{array}$ \\
\hline M3c & $\begin{array}{l}\text { Bacillus sp. }(1 / 10) \\
\text { Corynebacterium sp. }(1 / 10) \\
\text { K. pneumoniae }(1 / 10) \\
\text { S. aureus }(1 / 10) \\
\text { S. epidermidis }(1 / 10) \\
\text { S. lugdunensis }(1 / 10) \\
\text { S. xylosus }(1 / 10)\end{array}$ & $\begin{array}{l}\text { S. aureus }(1 / 3) \\
\text { Bacillus } \text { sp. }(1 / 2) \\
\text { S. intermedius }(1 / 2) \\
\text { E. coli }(1 / 10) \\
\text { Pseudomonas } \mathrm{sp} .(1 / 10) \\
\text { S. chromogenes }(1 / 10) \\
\text { S. saprophyticus }(1 / 10)\end{array}$ \\
\hline M3p & $\begin{array}{l}\text { Bacillus sp. }(1 / 10) \\
\text { K. pneumoniae }(1 / 10) \\
\text { S. lugdunensis }(1 / 10) \\
\text { S. saprophyticus }(1 / 10) \\
\text { S. xylosus }(1 / 10)\end{array}$ & $\begin{array}{l}\text { S. aureus }(5 / 10) \\
\text { Bacillus sp. }(1 / 10) \\
\text { Corynebacterium }(1 / 10) \\
\text { S. lugdunensis }(1 / 10) \\
\text { S. saprophyticus }(1 / 10)\end{array}$ \\
\hline M4c & $\begin{array}{l}\text { S aureus }(2 / 10) \\
\text { S. chromogenes }(2 / 10) \\
\text { Bacillus sp. }(1 / 10) \\
\text { Micrococcus sp. }(1 / 10) \\
\text { S. lugdunensis }(1 / 10)\end{array}$ & $\begin{array}{l}\text { Bacillus sp. }(5 / 10) \\
\text { Micrococcus }(2 / 10) \\
\text { S. intermedius }(2 / 10) \\
\text { S. aureus }(1 / 10) \\
\text { S. epidermidis }(1 / 10)\end{array}$ \\
\hline M4p & $\begin{array}{l}\text { S. chromogenes }(3 / 10) \\
\text { Micrococcus sp. }(2 / 10) \\
\text { S. aureus }(1 / 10) \\
\text { S. epidermidis }(1 / 10) \\
\text { S. saprophyticus }(1 / 10)\end{array}$ & $\begin{array}{l}\text { S. aureus }(4 / 10) \\
\text { Bacillus } \mathrm{sp} .(3 / 10) \\
\text { Micrococcus } \mathrm{sp} .(1 / 10) \\
\text { Pseudomonas } \mathrm{sp} .(1 / 10) \\
\text { S. epidermidis }(1 / 10) \\
\text { S. intermedius }(1 / 10) \\
\text { S. saprophyticus }(1 / 10)\end{array}$ \\
\hline
\end{tabular}

M1 = antes da tricotomia, M2 = após tricotomia, M3c = quatro minutos após a antissepsia com clorexidina M3p = com polivinilpirrolidona iodada, M4c = duas horas após a antissepsia cutânea com clorexidina, M4p = com polivinilpirrolidona iodada, Grupo $1=$ submetidas a um banho 24 horas antes da cirurgia, Grupo II = não submetidas a um banho 24 horas antes da cirurgia. 
GRUPO I

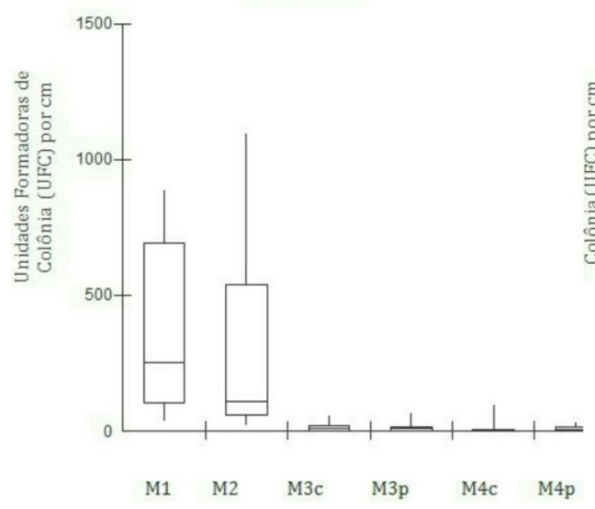

GRUPO II

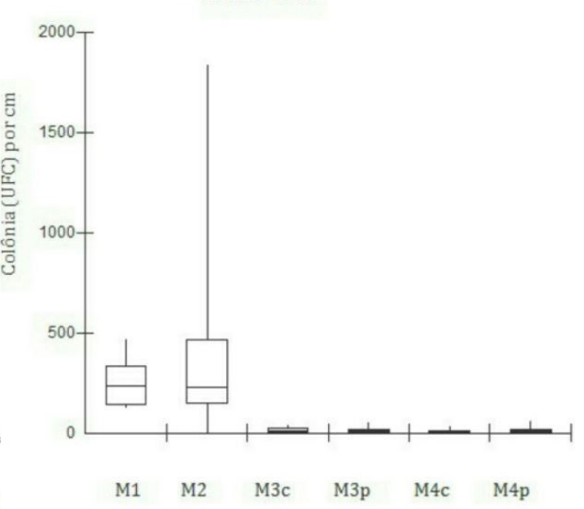

Fig.1. Unidades formadoras de colônia (UFC) por $\mathrm{cm}^{2}$ encontradas na pele de cadelas submetidas à ovariohisterectomia que foram (Grupo I) ou não (Grupo II) submetidas a um banho 24 horas antes da cirurgia, nos momentos: antes (M1) e após a tricotomia (M2), quatro minutos após a antissepsia com clorexidina (M3c) e com polivinilpirrolidona iodada (M3p) e duas horas após a antissepsia com clorexidina (M4c) e com polivinilpirrolidona iodada (M4p).
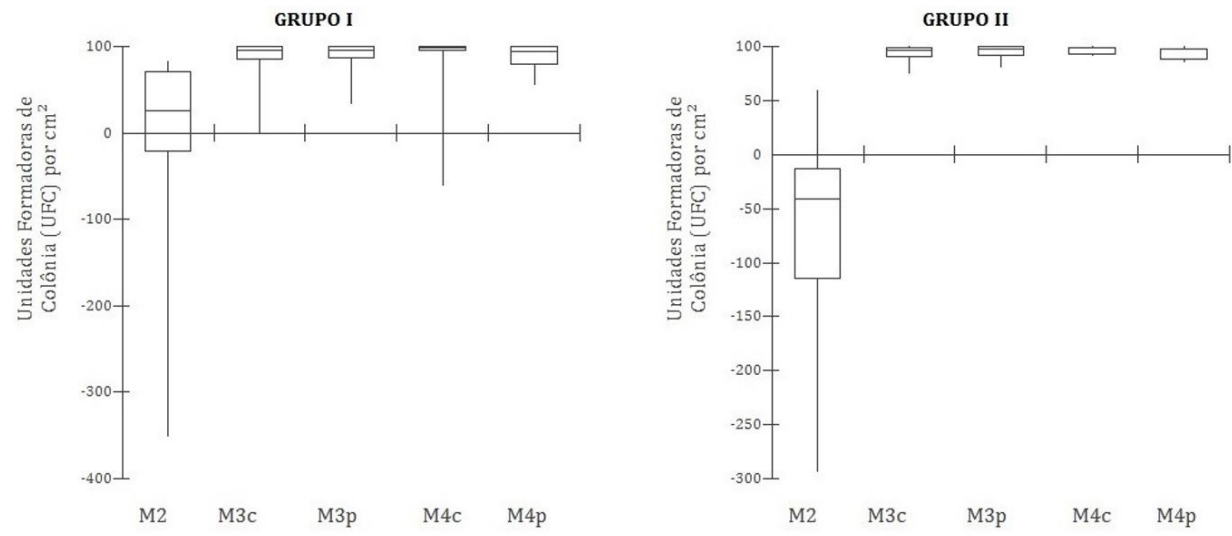

Fig.2. Medianas ( \pm desvios interquartílicos) da redução de unidades formadoras de colônia (UFC) por $\mathrm{cm}^{2}$ (\%) após a tricotomia (M2), quatro minutos após a antissepsia com clorexidina (M3c) e com polivinilpirrolidona iodada (M3p) e duas horas após a antissepsia com clorexidina (M4c) e com polivinilpirrolidona iodada (M4p), em cadelas submetidas à ovariohisterectomia que foram (Grupo I) ou não (Grupo II) submetidas a um banho 24 horas antes da cirurgia.

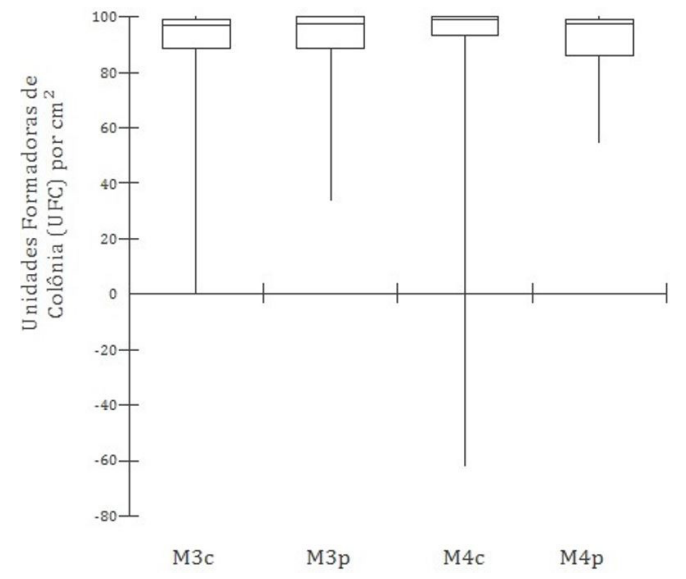

Fig.3. Medianas ( \pm desvios interquartílicos) da redução de unidades formadoras de colônia (UFC) por $\mathrm{cm}^{2}$ (\%) quatro minutos após a antissepsia cutânea com clorexidina (M3c) e com polivinilpirrolidona iodada (M3p) e duas horas após a antissepsia com clorexidina (M4c) e com polivinilpirrolidona iodada (M4p), em cadelas submetidas à ovariohisterectomia, independente de terem ou não sido submetidas a um banho 24 horas antes da cirurgia.
Após realização da tricotomia (M2), observou-se nas amostras do Grupo I medianas de redução microbiana de 26,48\%, enquanto nas do Grupo II ocorreu aumento de 41,19\% no número de colônias bacterianas, indicando diferença estatística significativa $(\mathrm{p}<0,05)($ Fig.2). Quanto aos demais momentos experimentais, as comparações entre os grupos não foram estatisticamente significativas $(p>0,05)$.

Não houve diferença estatística $(p>0,05)$ quanto ao percentual médio de redução bacteriana (Fig.3).

Dos 20 animais avaliados, 3 (15\%), sendo 2 animais do Grupo I e 1 do Grupo II apresentaram reação alérgica ao PVP-I, manifestadas por eritema, edema e pápula, não sendo observada nenhuma reação à clorexidina.

\section{DISCUSSÃO}

Diversas bactérias foram isoladas da pele das cadelas no presente estudo. Em ambos os grupos, foi observada a presença de bactérias residentes e transitórias no $M 1$, revelando que mesmo com a realização do banho prévio, várias bactérias podem ser encontradas. 
Imediatamente após a tricotomia, verificaram-se também diversos tipos de bactérias na pele canina. Silva et al. (2000) observaram Staphylococcus sp., Micrococcus sp., Bacillus sp., Corynebacterium sp., Proteus sp., Pseudomonas sp., Escherichia coli e Acinetobacter sp.; Lambrechts et al. (2004) observaram Staphylococcus intermedius, Staphylococcus spp., Bacillus spp., Acinetobacter spp. e Staphylococcus aureus. Estes resultados são semelhantes ao encontrado no presente estudo, indicando que a microbiota cutânea destes animais é pouco variável.

Após o uso da clorexidina (M3c), em ambos os grupos foi observada resistência de 4 gêneros bacterianos, discordando de Monteiro et al. (2001), onde o único gênero resistente foi Bacillus sp., o que, segundo os autores, pode ser justificado pelo espectro de ação da clorexidina que não atua em microrganismos que esporulam. No presente estudo a resistência verificada aplicou-se tanto às bactérias que esporulam, quanto às que não esporulam, fato que pode estar relacionado à concentração do antisséptico utilizado $(0,5 \%)$ que era inferior a dos autores citados (2\%). Evans et al. (2009) ao utilizar a clorexidina em 4 concentrações $(1 \%, 2 \%, 3 \%$ e $4 \%)$ observou que quanto maior a concentração, maior a eficácia.

As bactérias observadas após o uso da PVP-I (M3p), em ambos os grupos, denotam que assim como o ocorrido com a clorexidina, alguns microrganismos são resistentes a este antisséptico. Araújo et al. (2013) observaram em seu estudo o crescimento de Staphylococcus sp., Streptococcus sp., E. coli e cocos gram-negativos antes da antissepsia e, após a realização da mesma com PVP-I, verificou-se que apenas Streptococcus sp. foi destruído pelo antisséptico. Monteiro et al. (2001) que observaram a presença de E. coli, Proteus mirabilis, Bacillus sp., S. aureus e Streptococcus sp. antes da utilização, constataram que o PVP-I além de ter sido efetivo conta Streptococcus sp., eliminou também E. coli e Proteus mirabilis. Estes achados sugerem que o espectro de ação do PVP-I pode variar, podendo estar relacionado não apenas a espécie e sim aos fatores intrínsecos da bactéria isolada.

Nos momentos M4c e M4p também foram encontrados diversos tipos bacterianos em ambos os grupos. Algumas bactérias que estavam presentes em M3c e M3p não foram mais observadas, o que pode estar relacionado com a necessidade de um maior tempo de exposição da bactéria ao antisséptico para sua eliminação. Em contrapartida, bactérias que haviam sido destruídas em M3c e M3p, voltaram a aparecer em M4c e M4p, possivelmente devido ao efeito residual reduzido do antisséptico, que permitiu uma recolonização provavelmente a partir da pele circunvizinha à área tricotomizada.

Arias et al. (2013) conferiram a presença de Pseudomonas sp., Streptococcus sp., Acinetobacter sp. e um bacilo gram-negativo associados a infecções cirúrgicas de cães e gatos. Em humanos, infecções cirúrgicas causadas por Pseudomonas aeruginosa, Staphylococcus aureus, Escherichia coli e Klebsiella pneumoniae já foram descritas (Lima et al. 2007, Nogueira et al. 2009). Percebe-se que as bactérias descritas anteriormente como promotoras de infecção cirúrgica em animais e humanos foram isoladas da pele das cadelas analisadas neste trabalho, contudo, das isoladas em infecções de cães e gatos, apenas a Pseudomonas sp. não foi eliminada com o uso de antissépticos. Vale salientar ainda, que a simples presença de bactérias no sítio cirúrgico não indica grande risco de infecção, pois é necessário que se atinja o nível crítico de contaminação bacteriana de $10^{5}$ bactérias/g de tecido para que uma infecção se instale (Dunning 2007). Além disso, a presença de fatores de risco no paciente também deve ser considerada (Nicholson et al. 2002).

Quanto à ação do banho prévio, embora na maioria dos momentos os grupos não tenham diferido entre si, a diferença verificada no M4c indica a importância da sua realização, pois sugere que, embora o banho aparentemente não interfira na contaminação trans-cirúrgica, sua ausência pode facilitar a contaminação pós-cirúrgica. Araújo et al. (2013) acreditam que o alto valor de UFC observado antes da aplicação de antissépticos em seu estudo pode ter sido relacionado à ausência do banho pré-operatório porém, mesmo com a ausência do banho o número de colônias observadas foi inferior a $10^{5}$ bactérias/g de tecido.

A redução da contagem bacteriana conferida após a realização da tricotomia se mostrou eficiente nos animais submetidos ao banho (Grupo I), uma vez que houve decréscimo no número de UFC após execução da mesma. Em contrapartida, observou-se no Grupo II aumento significativo no número de bactérias, o qual pode ter sido ocasionado pelo carreamento de bactérias do pelo sujo para a pele, devido ao maior contato pelo-pele que ocorre durante a tricotomia. Assim sendo, evidencia-se a importância do banho prévio ao procedimento cirúrgico, tendo em vista que o pelo após o banho apresenta colonização microbiana reduzida, transportando assim menor número de bactérias para a pele durante a tricotomia. Contudo, segundo Paula \& Carvalho (2010) a tricotomia pode aumentar o risco de infecção, pois causa lesões epidérmicas rapidamente colonizadas por bactérias residentes, principalmente se realizada através de navalha (Fossum 2013), como no presente estudo.

A ausência de significância estatística na comparação da redução média de bactérias, entre os momentos M3c, M3p, M4c e M4p, em ambos os grupos, mostra que independentemente de o animal ter sido ou não submetido ao banho prévio, a redução de bactérias após o uso dos antissépticos foi semelhante. Porém, este achado pode não estar relacionado à ineficiência do banho prévio, e sim à eficácia dos antissépticos utilizados.

A mensuração do percentual médio de redução bacteriana após a aplicação dos antissépticos mostrou que ambos foram eficientes na antissepsia do campo cirúrgico 4 minutos e 2 horas após sua aplicação, quando a amostra englobou tanto animais submetidos quanto não submetidos ao banho 24 horas antes do procedimento cirúrgico. Silva et al. (2000) em seu estudo com clorexidina a $4 \%$ e tintura de iodo a $2 \%$ também observaram redução bacteriana adequada em até 2 horas após a aplicação. Estudo realizado em humanos para comparar a eficácia do gluconato de clorexidina $2 \%$ e do PVP-I 10\% na prevenção da infecção cirúrgica mostrou que não houve diferença entre os antissépticos (Park et al. 2017). Desta forma, pode-se constatar que a utilização de ambos os antissépticos pode ser realizada com segurança para redução de bactérias em procedimentos cirúrgicos, uma vez que conferiram ação satisfatória após 4 minutos, bem como efeito residual de 2 horas mesmo na presença de sangue e fluidos existentes no procedimento de ováriohisterectomia eletiva de cadelas.

As reações cutâneas observadas em alguns animais foram desencadeadas pela PVP-I, embora Moriya \& Módena (2008) citem que os iodóforos raramente provocam reações alérgicas. Estas alterações também não foram o descritas por Monteiro et al. (2001) que realizou antissepsia com a PVP-I 
10\% em 5 animais. De acordo com Quinn et al. (2005) um antisséptico ideal não deve causar irritação local, portanto, quanto a este aspecto, houve superioridade na antissepsia realizada com a clorexidina, onde não foi encontrada reação alérgica em nenhum animal.

\section{CONCLUSÕES}

Conclui-se que diversos tipos de bactérias podem ser isoladas da pele de cadelas submetidas ou não ao banho prévio e que, mesmo após o uso de antissépticos, esta microbiota permanece variada.

O banho prévio à cirurgia reduz a contagem microbiana da pele do campo operatório apenas após 2 horas de antissepsia com clorexidina.

A tricotomia é mais eficaz na redução desta contagem quando o animal é submetido ao banho previamente à cirurgia, e a eficácia antisséptica e o efeito residual da clorexidina $0,5 \%$ são iguais aos do PVP-I 10\%, independentemente de o animal ser ou não submetido ao banho previamente à cirurgia.

\section{REFERÊNCIAS}

Araújo S.B., Mello A.C., Monteiro N.M.O., Stipp D.T. \& Buquera L.E.C. 2013. Avaliação bacteriológica do sítio cirúrgico antes e após a antissepsia e ao final do procedimento cirúrgico. Acta Vet. Bras. 7(1):104-106.

Arias M.V.B., Aiello G., Battaglia L.A. \& Freitas J.C. 2013. Estudo da ocorrência de infecção hospitalar em cães e gatos em um centro cirúrgico veterinário universitário. Pesq. Vet. Bras. 33(6):771-779. <http://dx.doi.org/10.1590/ S0100-736X2013000600014>

Bernis Filho W.O., Rezende C.M.F., Abreu V.L.V. \& Bernis V.M.O. 1998. Infecções hospitalares em feridas cirúrgicas de pequenos animais. Arq. Bras. Med. Vet. Zootec. 50:127-132.

Braga D.P. 2008. Incidência e fatores de risco associados à infecção do sítio cirúrgico na clínica de cães e gatos do hospital veterinário da Universidade Federal de Viçosa. Dissertação de Mestrado. Disponível em <http:// locus.ufv.br/bitstream/handle/123456789/4981/texto\%20completo. pdf?sequence=1\&isAllowed=y> Acesso em 7 dez. 2016.

Braga D.P., Borges A.P.B., Carvalho T.B., Santos L.C. \& Corsini C.M.M. 2012. Antibioticoprofilaxia em cirurgias de cães e gatos: necessidade e realidade. Revta Ceres 59(6):758-764. <http://dx.doi.org/10.1590/ S0034-737X2012000600004>

Cockshutt J. 2007. Princípios de assepsia cirúrgica, p.149-155. In: Slatter D. (Ed.), Manual de Cirurgia de Pequenos Animais. $3^{\text {a}}$ ed. Manole, São Paulo.

Delucia R. 2007. Farmacologia Integrada. 3ํㅡㄹ. ed. Revinter, Rio de Janeiro. 701p.

Dunning D. 2007. Infecção da ferida cirúrgica e uso de antimicrobianos, p.113-122. In: Slatter D. (Ed.), Manual de Cirurgia de Pequenos Animais. 3ae ed. Manole, São Paulo.

Evans L.K.M., Knowles T.G., Werrett G. \& Holt P.E. 2009. The efficacy of chlorhexidine gluconate in canine skin preparation: practice survey and clinical trials. J. Small Anim. Pract. 50(9):458-465. <http://dx.doi. org/10.1111/j.1748-5827.2009.00773.x><PMid:19769666>

Fossum T.W. 2013. Small Animal Surgery. 4th ed. Elsevier-Mosby, St Louis. $1640 \mathrm{p}$.

Garcia R. 2010. Surgical skin antisepsis. Perioper. Nurs. Clin. 5(4):457-477. <http://dx.doi.org/10.1016/j.cpen.2010.07.004>

Ibanéz N. \& Casamada N. 2005. Chlorhexidine: the ideal antiseptic. Revta Enferm. 28(9):31-35. <PMid:16238008>

Lambrechts N.E., Hurter K., Picard J.A., Goldin J.P. \& Thompson P.N. 2004. A prospective comparison between stabilized glutaraldehyde and chlorhexidine gluconate for preoperative skin antisepsis in dogs. Vet. Surg.
33(6):636-643.<http://dx.doi.org/10.1111/j.1532-950X.2004.04086.x> $<$ PMid:15659020>

Lima M.E., Andrade D. \& Haas V.J. 2007. Avaliação prospectiva da ocorrência de infecção em pacientes críticos de Unidade de Terapia Intensiva. Revta Bras. Terap. Intensiva 19(3):342-347. <http://dx.doi.org/10.1590/S0103507X2007000300013>

Magalini S., Pepe G., Panuzi S., De Gaetano A., Abatini C., Di Giorgio A., Foco M. \& Gui D. 2013. Observational study on preoperative surgical field disinfection: povidone-iodine and chlorhexidine-alcohol. Eur. Rev. Med. Pharmacol. Sci. 17(24):3367-3375. <PMid:24379069>

Monteiro V.L.C., Coelho M.C.O.C., Mota R.A., Carrazzoni P.G., Tenório Filho F., Lima E.T. \& Monteiro F.G.C. 2001. Anti-sepsia de pele de cães utilizandose clorhexidina a $2 \%$, povidine a $10 \%$ e álcool iodado a $5 \%$. Ciênc. Anim. Bras. 11(1):7-12.

Moriya T. \& Módena J.L.P. 2008. Assepsia e antissepsia: técnicas de esterilização. Medicina, Ribeirão Preto, 41(3):261-269. <http://dx.doi.org/10.11606/ issn.2176-7262.v41i3p265-273>.

Murray P.R. 1999. Manual of Clinical Microbiology. 7th ed. American Society for Microbiology, Washington. 1773p.

Nicholson M., Beal M., Shofer F. \& Brown D.C. 2002. Epidemiologic evaluation of postoperative wound infection in clean-contaminated wounds: a retrospective study of 239 dogs and cats. Vet. Surg. 31(6):577-581. <http:// dx.doi.org/10.1053/jvet.2002.34661><PMid:12415527>

Nogueira P.S.F., Moura E.R.F., Costa M.M.F., Monteiro W.M.S. \& Brondi L. 2009. Perfil da infecção hospitalar em um hospital universitário nosocomial. Revta Enferm. UERJ 17(1):96-101.

Oliveira A.C., Martins M.A., Martinho G.H., Clemente W.T. \& Lacerda R.A. 2002. Estudo comparativo do diagnóstico da infecção do sítio cirúrgico durante e após a internação. Revta Saúde Públ. 36(6):717-722. <http:// dx.doi.org/10.1590/S0034-89102002000700009>

Oliveira F.B.M., Lima L.M., Moura M.E.B., Nunes B.M.V.T. \& Oliveira B.M. 2011. Uso indiscriminado de antibióticos e resistência microbiana: uma reflexão no tratamento das infecções hospitalares. Revta Interdiscipl., UFMG 4(4):72-77.

Osuna D.J., DeYoung D.J. \& Walker R.L. 1990. Comparison of three skin preparation techniques. 2. Clinical trial in 100 dogs. Vet. Surg. 19(1):20-23. <http://dx.doi.org/10.1111/j.1532-950X.1990.tb01137.x><PMid:2405580>

Park H.M., Han S.S., Lee E.C., Lee S.D., Yoon H.M., Eom B.W., Kim S.H., Ryu K.W., Park S.J., Kim Y.W. \& Park B. 2017. Randomized clinical trial of preoperative skin antisepsis with chlorhexidine gluconate or povidone-iodine. Brit. J. Surg. 104(2):e145-150. <http://dx.doi.org/10.1002/bjs.10395> <PMid:27879993>

Paula R.A. \& Carvalho M.V.H. 2010. Cuidados com a região a ser operada. Perspect. Méd., Fac. Med. Jundiaí, 21(2):33-38.

Quinn P.J., Donnelly W.J.C., Carter M.E. \& Markey B.K. 2005. Microbiologia Veterinária e Doenças Infecciosas. Artmed, Porto Alegre. 512p

Reis U.O.P. 2014. Controle da infecção hospitalar no centro cirúrgico: revisão integrativa. Revta Baiana Enferm. 28(3):303-310.

Rocha J.J.R. 2008. Infecção em cirurgia e cirurgia das infecções. Medicina, Ribeirão Preto, 41(4):487-490. <http://dx.doi.org/10.11606/issn.21767262.v41i4p487-490>.

Silva A.C., Aleixo G.A.S. \& Potier G.M.A. 2009. Profilaxia das infecções, p.4966. In: Tudury A.E. \& Potier G.M.A. (Eds), Tratado de Técnica Cirúrgica Veterinária. Medvet, São Paulo.

Silva D.A.R., Costa M.M., Vargas A.C., Alievi M.M., Schossler E.W. \& Silva T.R. 2000. 0 gluconato de clorexidina ou o álcool-iodo-álcool na anti-sepsia de campos operatórios em cães. Ciência Rural 30(3):431-437. <http:// dx.doi.org/10.1590/S0103-84782000000300010> 